\title{
Literature-technology-media: towards a new technography
}

\author{
James Purdon
}

\begin{tabular}{|l|l|}
\hline Date of deposit & 06112017 \\
\hline Document version & Author's accepted manuscript \\
\hline Access rights & $\begin{array}{l}\text { C } 2017 \text { John Wiley \& Sons Ltd. This work is made available online } \\
\text { in accordance with the publisher's policies. This is the author } \\
\text { created, accepted version manuscript following peer review and } \\
\text { may differ slightly from the final published version. }\end{array}$ \\
\hline $\begin{array}{l}\text { Citation for } \\
\text { published version }\end{array}$ & $\begin{array}{l}\text { Purdon, J. (2017). Literature-technology-media: towards a } \\
\text { new technography. Literature Compass, Early View. }\end{array}$ \\
\hline $\begin{array}{l}\text { Link to published } \\
\text { version }\end{array}$ & https://doi.org/10.1111/lic3.12432 \\
\hline
\end{tabular}

Full metadata for this item is available in St Andrews Research

Repository at: https://research-repository.st-andrews.ac.uk/

\section{St Andrews Research Repository}




\section{Literature-Technology-Media: Towards a New Technography}

This essay gives a brief account of some recent theoretical accounts of the technological mediation of culture - in particular the distinct but overlapping discourses of "media archaeology" and "cultural techniques" - and considers the implications of this recent technological or medial turn for literary studies. Media archaeology and cultural techniques have risen to institutional prominence in the last decade as energetic and influential disciplinary frameworks for the study of archives, protocols, devices, mechanisms, networks, infrastructures, and other technical systems. Yet literature has generally remained tangential to these inquiries, which have at times sought to define their investigations of technological culture explicitly in opposition to "textuality", "discursivity", or "literary studies".

My purpose here is to offer a measure of resistance to this binary distinction, which appears to stem from a view of literary scholarship as a discipline tainted by Enlightenment anthropocentrism. Much of the new media scholarship, following the logic of what Richard Grusin (2015) has called the "nonhuman turn", has nurtured a certain skepticism about literature on the basis that it forms one of the pillars of the traditional humanities, the study of which has tended to privilege mind over body, spirit over matter, message over medium, human knowledge over non-human (or post-human) agency. Literary studies, according to this view, is based in and reinforces Enlightenment's centring of the human subject, and its primary methodology of hermeneutic analysis remains indifferent to the crucial role played by technological mediation in the emergence and development not only of individual cultural forms, but of the ontological category of "the human".

To the contrary, I argue that the apparent antagonism between textuality and technology — a term that originates in the rhetorical theory of the ancient world - is itself a legacy of the Enlightenment and the first Industrial Revolution, when the classical principle of techne was replaced by a modern division between forms of theoretical and practical knowledge. Only by dealing with textuality and technicality as parts of the same dialectical process, I argue, can we move beyond that disciplinary and institutional antagonism to recognise their development as part of a single technographic history.

\section{Machine Agency: From Marinetti to Cultural Techniques}


If the cultural agency of technology has become a pressing concern for contemporary critical theory, the idea that technology might possess such agency is by no means new. Indeed, it has been a live topic in literary culture at least since the beginning of the twentieth century, when Filippo Tommaso Marinetti urged his followers to turn their attention away from the psychological qualities of man to magnify the technical object. Humanism, psychology, spirit, subjectivity: none of this, Marinetti insisted, was of any further use to the Futurist writer. Instead, what mattered was matter. "The solidity of a strip of steel interests us for itself; that is, the incomprehensible and nonhuman alliance of its molecules or its electrons that oppose, for instance, the penetration of a howitzer." Of even greater interest were those mechanical assemblages or co-ordinations of matter which seemed to demonstrate agency in more dynamic ways. "We want to make literature out of the life of a motor," he wrote, "a new instinctive animal whose general instincts we will know when we have learned the instincts of the different forces that make it up" (Marinetti, 1912, p. 87).

Despite Marinetti's barnstorming 1912 tour of London, the anglophone world did not prove particularly receptive to his machine-age gospel. On the whole, audiences were genially amused rather than shaken to their bourgeois foundations. Nonetheless, the "Technical Manifesto of Futurist Literature" suggests that the "post-human" turn of contemporary media theory may represent less a clean break with the naïve anthropocentrism of the traditional humanities than the recurrence of a profound and widespread dissatisfaction about the failure of cultural forms to adapt to changing views of the relations between humans and technological objects. Emerging from the chrysalis of modernism and postmodernism, cultural criticism finds itself calling for yet another repudiation of the human.

After the Second World War, howitzers and steel plate seemed even less appealing than they had to Marinetti's audiences in 1912. The precariousness of human agency had everywhere been demonstrated in its subordination to the demands of belligerent states, while the idea of machine agency tended to figure as profoundly disturbing. Fresh memories of technological genocide, mechanized warfare, and nuclear weapons nurtured visions of a future filled with killer robots and atomic automata. According to the philosopher Gilbert Simondon (1958), such fears implied a widespread misattribution of agency to technological objects, a misattribution that might have had something to do with the diminution of personal agency which many citizens had experienced during wartime. "No cultivated man," Simondon wrote, "would allow himself to speak of things or persons painted on a canvas as veritable realities with an interior life and a will, good or bad. Despite this, the cultivated man does allow himself to speak of machines which threaten mankind, as if he were attributing to these objects a soul and a separate and autonomous existence which grants them the possession of feelings and of intentions towards mankind" (p. 3). For Simondon, machines were not 
to be thought of as something fundamentally other than human beings, but as physical manifestations of human relations and objectives. Fears of machine agency thus expressed a widespread cultural failure to understand that "in technical reality there is a human reality" (p. 1).

Recent theories of technological media have usually begun not from Simondon's account of the human reality in machines, but from the work of Friedrich Kittler, whose Gramophone, Film, Typewriter (1999) set a new bearing with its bold opening announcement that "media determine our situation" (p. xxxix). One way of understanding this statement is as the reverse of Simondon's position: Kittler insists not that technical reality is fundamentally part of human reality, but that human reality was always already technical, or (to put it another way) that our notions of what belongs properly to human reality derive from historically contingent arrangements of technological reality. Kittler's influence since the mid-1980s is difficult to overstate, particularly in Englishspeaking countries where his work has come to serve both as a catalyst for new inquiries into the mutual constitution of technology and culture and (less straightforwardly) as the paradigmatic instance of so-called "German Media Theory". If that characterization certainly misrepresents the range and diversity of technology and media scholarship in German-speaking countries, it is equally certain that the "Kittler-effect" has been crucial in driving the recent boom in technological scholarship across the humanities.

Yet Kittler himself remained somewhat circumspect on the subject of machine agency. If media determine our situation, they do so in part because, in the age of optical and acoustic storage media, the "essence" of humanity can no longer be understood as residing in embodied, self-sufficient subjects: instead it "escapes into apparatuses" (p. 16). The ghost in Kittler's machine turns out to be a spectral form of humanity, albeit a humanity that had hitherto failed to recognise the historical and technological contingency of its own ontological status. Most scholarly extensions of Kittler's work have likewise been too sophisticated to make claims for ghostly presences in technology. But, like Kittler, they have generally sought explanations of cultural forms in technological structures.

The field of "media archaeology", in particular, has come to designate a set of practices and forms of scholarship built around a central concern with machine agency. In its most stringent formulations, such as that offered by Wolfgang Ernst (2013), media archaeology insists, moreso even than Kittler, on the priority of mechanism: "Media archaeology concentrates on the nondiscursive elements in dealing with the past: not on speakers but rather on the agency of the machine" (p. 45). Its key works — including Siegfried Zielinski's Deep Time of the Media (2008), Erkki Huhtamo and Jussi Parikka's collection Media Archaeology (2011), Parikka's various archaeological accounts of computer viruses, insect swarms, and geological materials, and the essays of Ernst — offer several quite different 
accounts of this archaeological approach. Within this body of work, however, two parallel (and perhaps contradictory) concerns are clear: a materialist emphasis on the the physical structures of technological devices and systems, and a Foucauldian rejection of teleology and continuity in favour of a cartographic tracing of variants, dead-ends, obsolete forms, and other marginal traces of the mediated life.

Media archaeology has not been entirely dismissive of "discursivity" (Parikka, for instance, has insisted that media archaeology "rummages textual, visual, and auditory archives as well as collections of artifacts, emphasizing both the discursive and the material manifestations of culture" (2011, p. 3)) - but it has not, so far, taken much interest in the specific discursive form of literature. Indeed, on those few occasions when media archaeology has dealt with literary subjects, it has struggled to overcome what amounts to a form of hardware-bias, defining literature not as a sequence of dynamic processes, but as an object of knowledge. In 2015, the online journal Jacket 2 sought responses to the question: "How can media archaeology inform literary studies?" (n.p.). The responses gathered from self-identifying media archaeologists constituted a valuable account of the possibilities of media archaeology, but often seemed to do so at the expense of misrepresenting literary studies as a discipline. There was, for instance, a strong emphasis on poetry as the exemplary instance of literature, with no discussion of prose texts or of performance contexts. One respondent noted that "media archaeology's most significant contribution to literary studies is the way it frees us from constantly, and only, interpreting content", as if hermeneutic analysis remained the sole or even the main interest of literary studies. Finally, Parikka and Jane Birkin's co-authored response argued that media archaeology should point the course away from literature to "an informational theory of literature as media: less hermeneutics, more Shannon and Weaver + information theory. [...] As we know by now, text is not for reading. It is for processing. Ask any machine reading system and it will tell you the same."

From the standpoint of literary studies, it might reasonably be objected that readers are not simply in the business of "processing" texts in the way a machine-reading system processes them, discovering certain sequences or patterns independently of others. Rather, readers process texts in the sense that in reading they involve themselves in sequences and patterns designed to produce particular cognitive, physical, and affective responses. (And since reading may also involve various kinds of misprision and contingency, design may only be part of the event of reading.) Readers, even scholarly ones, read in pursuit of more than just signals or data: as they process a novel or a poem, they are in turn processed by it. The more accurate analogy is perhaps not with the machine-reading of a literary text, with the aim of extracting data, but with the machine-reading of a program, which alters the configuration of the machine itself. The idea of the poem as the paradigmatic literary object; the idea 
that literary studies has mainly been concerned with the interpretation of content; the notion that literary works amount to data for processing or signals to be encoded and decoded; the treatment of literary works as valuable primarily as signposts pointing towards some other theoretical destination - none of these positions has been able to lay much claim to orthodoxy in literary studies since at least the early 1980s. And there is, perhaps, an irony here: for while media archaeology traces its roots to Kittler's inquiries into dynamically varying matrices of technological and textual agency, it has itself seemed content to positivise media and literature alike as objects or archives.

An alternative to the hardware-oriented investigations of media archaeology has begun to emerge in the form of "cultural techniques", which also has roots in German media theory. Cultural techniques is less well established in anglophone circles than media archaeology, but all signs point to its continued growth as a vigorous field. The two are not mutually exclusive; indeed, many scholars are active in both areas, which may be regarded as complementary or even continuous. The key publications so far include a special issue of Theory, Culture and Society edited by Geoffrey Winthrop-Young, Ilinca Iurascu, and Jussi Parikka in November 2013, and, more recently, Bernhard Siegert's Cultural Techniques: Grids, Filters, Doors, and Other Articulations of the Real (2015), translated by Winthrop-Young.

The theory of cultural techniques has concentrated less on hardware than on the processes through which a broadly-defined field of "culture" emerges from intricate operations conducted by humans and non-human entities together. Here, too, though, that emphasis falls on a reallocation of agency: "Clearly, from the vantage point of cultural techniques, the sovereign subject becomes disempowered, and it is things that are invested with agency instead." (Vismann, 2013, p. 86). Or, if not instead, then as well: Siegert (2015) draws on the sociology of Bruno Latour to describe a cultural technique as an "actor-network" including "technical objects and chains of operations [...] in equal measure" (p. 193). Cultural techniques can be understood as the myriad undirected, independent processes through which seemingly foundational aspects of human culture come into being. The study of cultural techniques emphasises the emergence of "culture" from specific practices before those practices have solidified into concepts which will later be misidentified as causes rather than effects: on inscription before it gives rise to a notion of language; on counting before it gives rise to a notion of number; on the marking of thresholds before those thresholds give rise to notions of interiority and exteriority. From this perspective, agency "is not a given but is constituted by and dependent on cultural techniques". In the theory of cultural techniques, emphasis falls on the production not of the human (as in Kittler) or of media (as in media archaeology), but of culture as an emergent property of interactions between entities. 
Siegert, in an invaluable historical account, traces the emergence of the theory of cultural techniques to German media theory's rejection of the poststructuralist turn of the 1980s. The "anti-hermeneutic" preoccupations of Kittler-era media analysis, he notes, had prepared the ground for a "posthermeneutic" study of the technological mediation of culture. Siegert (2013) has sharp words, in particular, for "the many literature scholars, philosophers, anthropologists and communication experts, who were suddenly forced to realize how much there was beyond the hermeneutic reading of texts when it came to understanding the medial conditions of literature and truth or the formation of humans and their souls" (p. 51). Yet it is clear from his earlier work, and in particular his Relays: Literature as an Epoch of the Postal System, that "literature" for him means, above all, the public and professional field of humane letters that emerged after the middle of the eighteenth century, preeminently in the work of his "master signifier", Goethe. Literature constitutes "an epoch of the postal system" for Siegert (1999) because the systematization of postal networks in eighteenth-century Europe helped to reconfigure the boundaries of the private individual and the public sphere, laying the foundations for "literature" as the transmission of an author's private subjectivity to and through a network of readers.

While Siegert's account of Germany's eighteenth-century communications system undoubtedly illuminates the role of one historically-specific apparatus in the emergence of concepts of authorship and textuality, as a theory of relations between literature and technological mediation it might be thought to beg the question. In other words, the cultural techniques of the postal system give birth to "literature" because "literature" is the name Siegert chooses to apply to the kinds of writing which have been engendered by the cultural technique of the postal system. From the perspective of an anglophone scholarship which has traditionally taken a rather broader view of "literature", this epochal circumscription will not do, for it stops short of acknowledging the operation of a broader historical dialectic between the concept of technology and the concept of literature which does not begin or end in Goethe's mailbox. I stress the importance of the anglophone context here not out of any inclination towards exceptionalism, but rather because it was in England, during the Industrial Revolution, that the crucial conceptual separation between textuality and technology took place. It is to an account of this transition that I now turn.

\section{The Technographic Dialectic}

In their introduction to The Social Construction of Technological Systems, Wiebe Bijker, Thomas Hughes and Trevor Pinch (1987) distinguish between three meanings of the word "technology": 
First, there is the level of physical objects or artifacts, for example, bicycles, lamps, and Bakelite. Second, "technology" may refer to activities or processes, such as steel making or molding. Third, "technology" can refer to what people know as well as what they do; an example is the "know-how" that goes into designing a bicycle or operating an ultrasound device in the obstetrics clinic. (p. 4)

Writing itself may be regarded as a technology, though one which now seems so fundamental to the history of our species that we have lost the tendency to think of it as such. It can indeed describe an artifact ("the writing of George Eliot"), the process that produces such an artifact ("I am writing a novel"), or the "know-how" activated in that process, which the ancient philosophers would have called its techne ("I teach writing to undergraduates").

Yet like most accounts of technology, the one given by Bijker, Hughes and Pinch leaves out the more complicated history of concepts sedimented in that set of definitions. In fact, when we speak about a "technology", we are reaching for a term that originally referred not to a device, or to a physical process, or even to a form of "know-how", but to a kind of text. To be more exact, we are reaching for a term that referred to a text considered as a kind of device, a device for thinking with, displaying, and understanding a particular verbal techne.

For the Greeks, tekhnologia meant not a domain of objects but a genre of discourse; not a mechanism or a physical implement, but a tool nonetheless: a technical description of a subject made in accordance with agreed principles. When, at the very beginning of his first-century CE treatise On the Sublime, Longinus (1907) insists that every "systematic treatise" requires both a "statement of the subject" and "an indication of the methods by which we may attain our end", his word for "systematic treatise" is $\tau \varepsilon \chi v o \lambda o \gamma i \alpha \varsigma$ (p. 41). And when, later the same century, Plutarch (1939) cautions that people talk too much about the subjects in which they feel themselves to be most expert, he notes that "the great reader" will prefer to spend all of his time "narrating tales", while "the literary expert" will

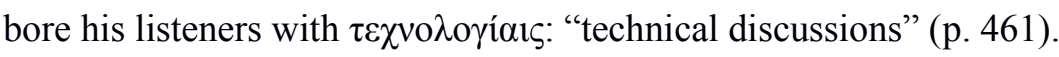

The earliest appearances of the term "technology" in seventeenth-century English likewise designated specialized uses of language. In particular, "technology" was used to denote sophisticated or abstruse jargon, as distinct from the pious plainness required in speaking of God. The scholar Isaac Casaubon (1612), for instance, cites the authority of the fourth-century Archbishop Gregory of Nazianzus, who denounced his contemporaries for their readiness to "dispute of spirituall things, and conuert Theologie into technology", making the study of divinity "a matter of learned, or artificiall discourse" 
(p. 7). Similarly, in the dedication to a sermon first preached in 1645, the Norfolk priest Edward

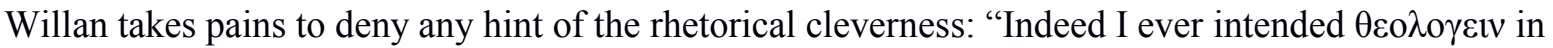

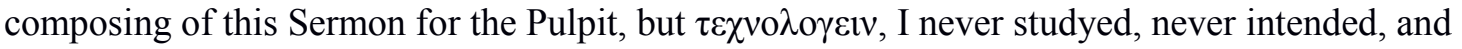
therefore cannot but admire, that any in that Auditory should admire it for Technologie (p. 28). Even Sir Thomas Browne, in Hydriotaphia, or Urne-Buriall (1658), has occasion to refer to the "Cabalisticall Technology" of Jewish mystical tradition (p. 192).

As Clifford Siskin (2016) has suggested, the spread of the term "technology" in early modern English tracks wider social and intellectual transformations over a period when informal, conversational forms of knowledge were gradually being subordinated to the kind of systematic rationality associated with print. Technology, Siskin points out, 'is the 'speaking of' (-ology) a 'techne,' that is, an 'art,' or 'method' or 'system.' [...] Technology, as the speaking of something that speaks to itself, thus became an embodiment of a silent and self-sufficient reason" (p. 38). From the end of the $17^{\text {th }}$ century onward, as specialized languages proliferated alongside new mechanical processes, the word "technology" began to be used to refer not to a systematic description of a field of knowledge or to the specialist jargon associated with a particular subject, but to the practical operations performed by physical systems. Since the most striking and innovative examples of such systems at that time were mechanical, "technology" soon came to be associated with the category of equipment used to perform such practical operations. In short order, a term for a discourse or a way of thinking and speaking was transformed into a term for a set of material structures and implements.

Technological innovation - particularly the new dominance of print - had helped to disseminate the new sense of "technology" as a matter of mechanical systems and operations rather than of verbal ones, so that by the middle of the eighteenth century this meaning was dominant. At around the same time, as John Guillory (2010) has noted, the arrangement of knowledge into mechanical and liberal arts which shared a basis in "the concept of techné" was superseded by a new arrangement of knowledge in which the "fine arts" were taught and studied as elements of aesthetic theory, which "excluded all mechanical arts as well as former liberal arts such as logic and rhetoric" (p. 346n). Thus the modern concepts of technology and of the arts, including literature, were purified and distinguished precisely through the exclusion of rhetoric as a form of knowledge which had hitherto been common to both.

In "Building Dwelling Thinking", Heidegger (2011) traces "techne" back to its Greek root tikto, which means (as he says) "to bring forth or to produce" but also (as he does not say) "to give birth", so that tikto combines that sense of intentional mediation which techne inherits from it with the kind of self-developing generation usually associated with its contrasting term (though not exactly its 
opposite), physis. "The Greeks", Heidegger continues, "conceive of techne, producing, in terms of letting appear. Techne thus conceived has been concealed in the tectonics of architecture since ancient times. Of late it still remains concealed, and more resolutely, in the technology of power machinery" (p. 253). To this Heideggerean delving, we can also add that the reconstructed proto-Indo-European root of techne is *teks-, which has to do with building or construction. *Teks- likewise lies behind the Latin verb texere, weaving, which gives rise to our own metaphor of the literary text.

We could call this historical relationship between the concepts of technology and literature a technological dialectic, were it not that the modern associations of the term "technology" serve unhelpfully to obscure the very process I have been describing. We have probably come too far to entertain much hope of reinstalling "technology" as a name for a specific kind of discursive operation, but it might yet be possible to recuperate the emphasis, present in the earliest definitions of "technology" and lost in the intervening centuries, on writing as the form of mediation through which human reality and technical reality are most readily understood to be mutually articulative. To mark this ambition, we might recuperate another term from the rhetoricians, to remind us that a union of the material and the symbolic is ingrained within the concept of technology itself from the earliest times.

Technography, like "technology", was once a term for a systematic treatise, specifically a treatise on the art of rhetoric. The author of the Rhetoric to Alexander, for instance - long attributed to Aristotle but probably the work of Anaximenes of Lampsacus - speaks of borrowing certain well-expressed principles from the authors ( $\tau \varepsilon \chi v o \gamma \rho \alpha ́ \varphi o v)$ of such treatises. So too Philostratus the Athenian, who in the Lives of the Sophists uses the same word to describe Caninius Celer, rhetoric teacher to the young Marcus Aurelius. In the nineteenth century, "technography" was occasionally used to describe written economic, sociological, or historical accounts of specific processes or devices - in other words, "technography" began to designate the kind of writing that had previously been designated by "technology" - and, more recently, it has been revived in a variety of academic contexts. In sociology, "technography" has been used to denote "an ethnographic approach emphasizing the technological dimension of a culture" (Wengenroth, 2008, p. 831) or, more simply, "an ethnography of technology" (Jansen \& Vellema, 2011, p. 169). For the anthropologist Paul Richards (2005), technography "describes technologies from the point of view of how they are actually used, and not from the perspective of how they are supposed to work" (p. 199). And the postmodern architectural theorist Marco Frascari (1990) has adopted the term to describe an ideal form of architectural drawing which serves not only to represent, but also to calculate and demonstrate, the multiple instrumental and symbolic relationships between an imagined structure and the realization of that structure in the world of physical objects. 
For Steven Connor (2016), technography is "a writing out of an operation that consists in that very writing"; in literary terms, this can be conceived as a way of thinking in and through written language, much as mathematical calculations can be conceived as a way of thinking in and through written numbers. Technography, he suggests, "is immanent, exploratory and procedural rather than declarative", and in this sense literature might be understood to be technographic "in the sense that it is ever more taken up with the kind of machinery that it itself is" (p. 18). Where Connor is interested in the artifice of literary writing as a kind of reflexive technological project, Sean Pryor and David Trotter (2016) conceive of technography as a specific attentiveness to the historical and theoretical aspects of the relationship between writing and technology. To think in terms of technography is therefore to cultivate an attentiveness "to the rhetoric sedimented in machines, to machines behaving rhetorically, to rhetoric that behaves mechanically, and to rhetoric behaving in pointed opposition to mechanism" (p. 16).

That "technography" already gives its imprimatur to inquiries that interest themselves in particular kinds of literary procedure and to ones that consider certain kinds of material mediation strikes me as a healthy sign: within the horizon of technography, our comparatively modern interest in the "literary" as a uniquely prized canon of writing might resolve into a new interest in questions of the relationship between technical procedures and rhetorical ones. "Technography" then would not aim to return us to thinking about primarily how media represent or how technologies are represented, nor would it revive the linguistic turn to think in poststructuralist terms about a world of limitless textuality. It would not lay claim to the systematization of an "ism", or indeed of an "-ology", but would rather seek a more radical conception of the symbiosis of the technical and the symbolic that is written into the concept of technology from the beginning. By giving a name to the dialectic of technological and textual production, technography reminds us of the textual origins of the technology concept, and of the constant work of mutual articulation performed by technology and writing throughout history. The oddity of the term may itself serve to encourage the investigation of how the textual and the technical combine within and reshape particular social contexts, and of how our ideas of what a text is, and what a technology is, are themselves constantly being revised.

Technography makes a claim for the importance not of discourse as such, but of a specific kind of discourse that prioritizes an awareness of the process of its own mediation; a kind of writing which seeks to bring to consciousness the technicity of text and the textuality of technics; the kind of writing which we have recently been inclined to call literature, but which encompasses symbolic operations — techniques, or indeed technics — across many media forms. Technography might, then, be best understood less as a method than as a resistance to settling at one or other end of the object-discourse axis established by the rise of aesthetics in the eighteenth century. Technography does not positivise 
terms like "literature" or "technology" or "media", but seeks to understand how those concepts are transformed in the emergence of specific technical and discursive potentials. Equally, technography does not positivise the discursive operations involved in the transformation of those concepts, but tries to understand how particular discursive possibilities are themselves shaped by technical means. Such an exploration of the mutual mediation of technology and literature might, then, be punctuated not with intervening commas, but with dashes that better suggest their weaving together or wiring up. Literature-Technology-Media: as an approach to how texts and technical systems write each other into existence, technography does not presuppose where, if anywhere, text begins, and the machine stops.

Literary works have never been simply purveyors of representational content, channels for messages or signals, or objects whose meanings can be made explicit either by traditional hermeneutics or by media analysis. This is not to suggest that works of literature always make a fetish of their own material media, but rather that literature is a name we have sometimes given to cases of writing which calibrate their formal processes with particular precision to the affordances and resistances of a specific environment of technological mediation. Such works not only reflect these environmental conditions, but perform their own supple and systematic theorizing about their own processes of technological mediation: formally (in the various specialized techniques of poetic, narrative, or dramatic composition), liminally (in paratextual forms of address), materially (by attuning themselves to the capacities of a particular medium such as the book, the recording, the performance, or the screen), and socially (in terms of the wider media environment of a given society). As they do so, they reconfigure the very concepts of technology and of literature. The new technological focus provided by disciplines like media archaeology and cultural techniques has helped us to remember that writing is technological, through and through. Yet it would be a mistake to let a focus on devices, systems, and techniques blind us to the fact that the converse is also true: technology is written, through and through. The task remains - for literary scholars, media archaeologists, and cultural technicians alike — to give due consideration to both parts of the technographic dialectic.

\section{Works Cited}

Bijker, W., Hughes, T., \& Pinch, T. (1987). The Social Construction of Technological Systems. Cambridge, MA and London: MIT Press.

Browne, T. (1658). Hydriotaphia, urne-buriall, or, a discourse of the sepulchrall urnes lately found in Norfolk. London: Henry Brome. 
Casaubon, I. (1612). The ansvvere of Master Isaac Casaubon to the epistle of the most reuerend Cardinall Peron. Translated out of Latin into English. London: Felix Kyngston for William Aspley

Connor, S. (2016). "How to do Things with Writing Machines", in Writing, Medium, Machine: Modern Technographies, ed. Sean Pryor and David Trotter: 18-34. London: Open Humanities Press. Online at $<$ http://stevenconnor.com/writingmachines.html $>$

Ernst, W. (2013). Digital Memory and the Archive. Minneapolis, MN: University of Minnesota Press Frascari, M. (1990). "A new angel/angle in architectural research: the idea of demonstration". Journal of Architectural Education 44:1 (November). 11-19

Guillory, J. (2010). "The Genesis of the Media Concept". Critical Inquiry 36:2 (Winter). 321-362.

Grusin, R. (2015). The Nonhuman Turn. Minneapolis, MN: University of Minnesota Press.

Heidegger, M. (2011). "Building Dwelling Thinking” [1951], in Basic Writings, London: Routledge Jacket 2 (2015). "How can media archaeology inform literary studies?" $<$ http://jacket2.org/commentary/how-can-media-archeology-inform-literary-studies>

Jansen, K., \& Vellema, S. (2011). “What is Technography?”, NJAS-Wageningen Journal of Life Sciences 57 (3): 169-177

Kittler, F. A. (1999). Gramophone, Film, Typewriter, trans. Geoffrey Winthrop-Young and Michael Wutz. Stanford, CA: Stanford University Press

Longinus (1907). On the Sublime, trans. W. Rhys Roberts, 2nd ed. Cambridge: Cambridge University Press.

Marinetti, F. T. (1912). "Technical Manifesto of Futurist Literature”, in R.W. Flint (ed.), Marinetti; Selected Writings, London: Secker \& Warburg, 1972

Parikka, J., \& Huhtamo, E. (2011). Media Archaeology: Approaches, Applications, and Implications. Berkeley and Los Angeles

Plutarch (1939). Moralia, vol. 6, trans. W. C. Helmbold. Cambridge, MA. Harvard University Press Pryor, S., \& Trotter, D. (2016). "Introduction”, in Writing, Medium, Machine: Modern Technographies, ed. Sean Pryor and David Trotter: 7-17. London: Open Humanities Press Richards, P. (2005). "Plant biotechnology and the rights of the poor: a technographic approach", in Melissa Leach, Ian Scoones, and Brian Wynne, Science and Citizens: Globalization and the Challenge of Engagement. London: Zed Books. 199-214.

Siegert, B. (1999). Relays: Literature as an Epoch of the Postal System, trans. Kevin Repp. Stanford, CA: Stanford University Press. (2015). Cultural Techniques: Grids, Filters, Doors, and Other Articulations of the Real, trans. Geoffrey Winthrop-Young. New York: Fordham University Press 
(2013). "Cultural Techniques: Or the End of the Intellectual Postwar Era in German Media Theory”, Theory, Culture, and Society 30:6 (November) [Special Issue: Cultural Techniques]. 48-65.

Simondon, G. (1958). Du mode d'existence des objets techniques. Paris: Aubier, Editions Montaigne; trans. Nina Mellamphy. University of Western Ontario, 1980.

Siskin, C. (2016). System: The Shaping of Modern Knowledge. Cambridge, MA: MIT Press

Wengenroth, U. (2008). “Technografie: Zur Mikrosoziologie der Technik” [review of Werner Rammert and Cornelius Schubert, Technografie: Zur Mikrosoziologie der Technik], Technology and Culture 49.3. 831-832

Winthrop-Young, G., Iurascu, I., \& Parikka, J. (eds.) (2013). Theory, Culture, and Society 30:6 (November) [Special Issue: Cultural Techniques]

Vismann, C. (2013). "Cultural Techniques and Sovereignty", Theory, Culture, and Society 30:6 (November) [Special Issue: Cultural Techniques]. 83-93

Willan, W. (1651). Six Sermons London: R. Royston

Zielinski, S. (2008). Deep Time of the Media: Toward an Archaeology of Hearing and Seeing 